\title{
Erratum to: Magnetic Resonance Imaging Evaluation of Noninflammatory Breast Cancer with Skin Involvement After Neoadjuvant Chemotherapy
}

\author{
Jeon-Hor Chen, $\mathrm{MD}^{1,2}$, Rita S. Mehta, $\mathrm{MD}^{3}$, O. Nalcioglu, $\mathbf{P h D}^{1}$, and M.-Y. Su, $\mathrm{PhD}^{1}$ \\ ${ }^{1}$ Center for Functional Onco-Imaging, University of California, Irvine, CA; ${ }^{2}$ Department of Radiology, China Medical \\ University Hospital, Taichung, Taiwan; ${ }^{3}$ Division of Hematology and Oncology, Department of Medicine, University of \\ California, Irvine, Irvine, CA
}

\section{ERRATUM TO: ANN SURG ONCOL DOI: $10.1245 /$ S10434-010-0974-7}

The author byline of the published letter-to-the-Editor entitled, "MR imaging evaluation of non-inflammatory breast cancer with skin involvement following neoadjuvant chemotherapy" (DOI 10.1245/s10434-010-0974-7) did not include author Rita S. Mehta, MD. Dr. Mehta had an equal contribution as the first author, Dr. Jeon-Hor Chen.

The correct author byline for this letter is:

Jeon-Hor Chen, MD, Rita S. Mehta, MD, O. Nalcioglu, $\mathrm{PhD}$, and M.-Y. Su, PhD

This letter was published online February 24, 2010.

The online version of the original article can be found under doi: 10.1245/s10434-010-0974-7.

(C) Society of Surgical Oncology 2010

Published Online: 2 June 2010

J.-H. Chen, MD

e-mail: jeonhc@uci.edu 